\title{
NEAR INFRARED IMAGING OF HYDROXYL WAVE STRUCTURE OVER AN OCEAN SITE AT LOW LATITUDES
}

\author{
M.J. Taylor and M.J. Hill \\ Physics Department, University of Southampton,
}

\begin{abstract}
Coordinated observations of wave structure in the near infrared hydroxyl $(\mathrm{OH})$ nightglow emission have been made from Maui, Hawaii using a suite of narrow angle and all-sky TV cameras. Two sets of data were obtained, the first in conjunction with the ALOHA-90 campaign and the second during the subsequent new moon period. Well formed, short period $(<20 \mathrm{~min})$ wave patterns of comparable morphology, dynamics and abundance to those regularly imaged from mid-latitude mountain sites were detected on several occasions. Although the Hawaiian islands comprise several high volcanic peaks, the patterns were not consistent with gravity waves generated by the interaction of strong winds with the local island topography. This suggests that other mid-latitude wave patterns may also not be of mountain origin. The wave patterns imaged during ALOHA-90 were of significantly lower contrast than those detected later. This effect may be related to changes in the characteristics of the middle atmosphere that occur shortly after the spring equinox.
\end{abstract}

\section{Introduction}

Photographic and low light TV observations of wave structure in the near infrared (NIR) $\mathrm{OH}$ nightglow emission (peak altitude $\sim 87 \mathrm{~km}$, halfwidth $5-8 \mathrm{~km}$ ) have been made from several mid-latitude sites for almost two decades [Peterson and Kieffaber, 1973; Moreels and Herse, 1977; Armstrong, 1986; Taylor et al., 1987]. Measurements have also been obtained at auroral latitudes [Clairemidi et al., 1985] and from within the arctic polar cap [Taylor and Henriksen, 1989]. The data frequently show extensive wave-like patterns exhibiting horizontal wavelengths shorter than $100 \mathrm{~km}$.

To date there is very little information available on mesospheric wave motions that occur at low latitudes. Peterson [1979] reported visual and near infrared photographic observations from Hawaii of two small scale wave events (termed ripples), but no details were given of any other wave patterns that may have been detected. Subsequent attempts to image wave structure at low latitudes from Puerto Rico $\left(18.5^{\circ} \mathrm{N}\right)$, during the AIDA '89 campaign were restricted by poor observing conditions.

These observations of the NIR and visible nightglow emissions from Hawaii allow the properties of short period mesospheric wave motions that occur at low latitudes over

Copyright 1991 by the American Geophysical Union. an oceanic site to be investigated and compared with those regularly observed at mid-latitudes.

\section{Observations and Results}

Observations were made from the Department of Energy (DOE) building, Haleakala Crater, Maui $\left(20.8^{\circ} \mathrm{N}\right.$, $156.2^{\circ} \mathrm{W}, 2970 \mathrm{~m}$ ), over two consecutive new moon periods; 18 March-4 April during the ALOHA-90 campaign, and 18-27 April to provide additional data on mesospheric wave activity shortly after the spring equinox. The high altitude and favourable weather during these periods provided excellent conditions for imaging structure in the faint nightglow emissions.

Four cameras were operated, three of which were broad band NIR OH imagers; a narrow field Isocon $\left(30^{\circ}\right)$, a medium field $\operatorname{CCD}\left(55^{\circ}\right)$, an all-sky Isocon $\left(180^{\circ}\right)$, and an all-sky "monochromatic imager" filtered to observe structure in the OI $(557.7 \mathrm{~nm}$ ) nightglow emission (peak altitude $\sim 95 \mathrm{~km}$ ). Further details of the instrumentation are given in the ALOHA-90 overview paper [Gardner, 1991]. On several occasions during this campaign, remarkably coherent but faint NIR wave patterns were imaged. Comparison with spectrometer observations confirmed that these displays were due primarily to variations in the $\mathrm{OH}$ emission [Taylor et al., 1991].

Figure 1 shows four examples of wave structure imaged by the CCD camera at low elevations $\left(\sim 15^{\circ}\right)$ during ALOHA-90. The wave patterns were clearest in the CCD data which had the highest signal-to-noise ratio. Measurements of the horizontal scale size and motion of each of these wave patterns are listed in Table 1. Figure 1a shows several faint coherent wave crests curving upwards from the eastern horizon. The image was obtained on 21 March at 11.34 UT and formed part of an extensive display that lasted for about 2 hours. The pattern had an average horizontal wavelength, $\lambda_{x}$, of $-25 \mathrm{~km}$ and moved with a speed, $v_{x}$, of $\sim 47 \mathrm{~ms}^{-1}$, indicating an apparent period, $\tau$, of $\sim 9 \mathrm{~min}$. A similar short period display $(\sim 12$ $\mathrm{min}$ ) is shown in Figure 1b. The pattern was detected on 24 March, also around noon UT, but to the south and west of the site. Unfortunately meteorological cloud (seen in the low elevation foreground of the picture) limited the observations this night.

Figure 1c shows another well developed wave display. The data were obtained at 12:16 UT on 30 March looking northwards. On this occasion images of wave structure were also made in the zenith indicating an extensive spatially coherent display over much of the sky (confirmed by the NIR all-sky observations). Initially faint structure was detected around 08:00 UT but it was not until later that the display became as conspicuous as shown in the 


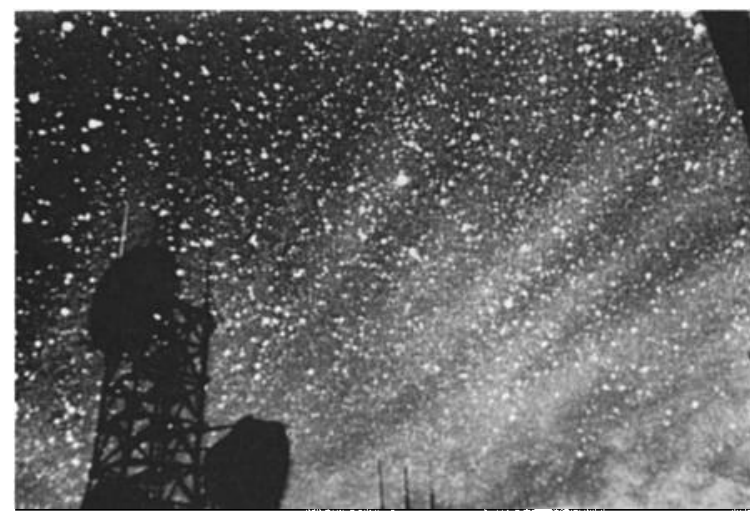

(a)

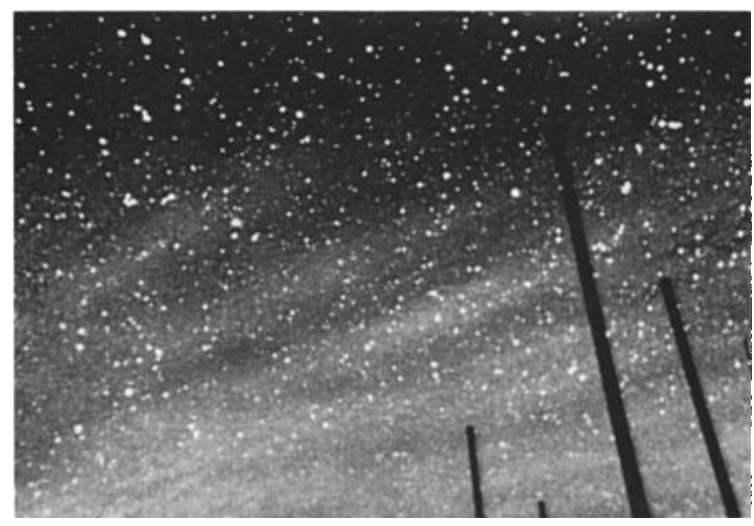

(c)

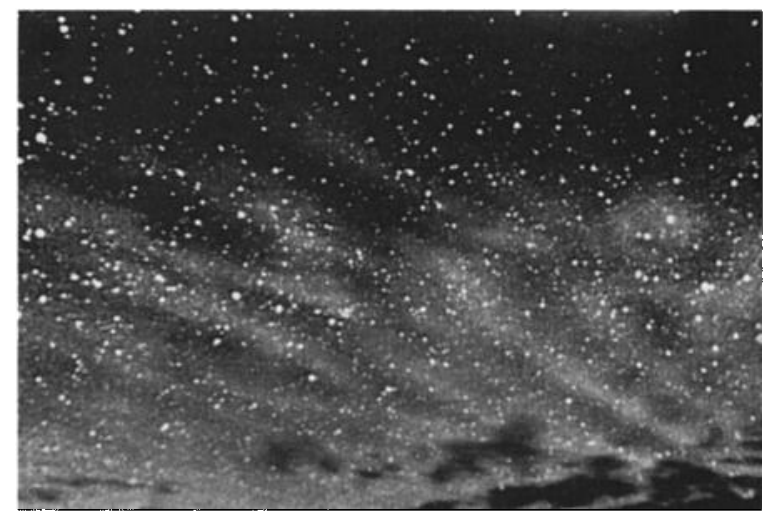

(b)

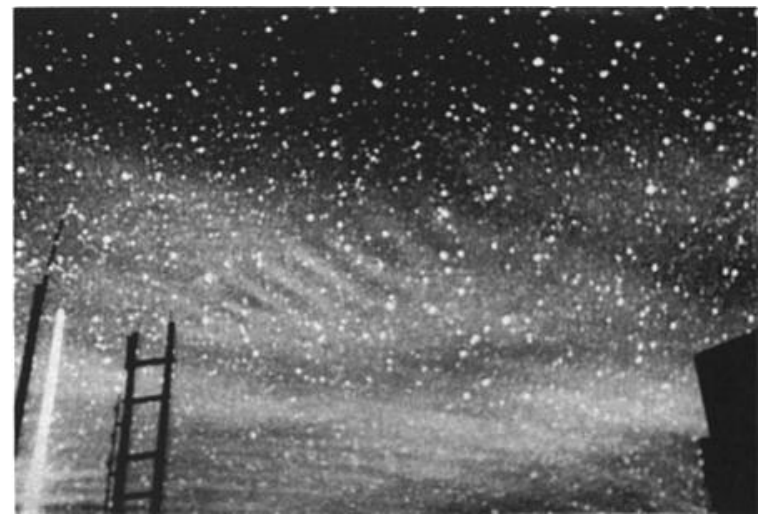

(d)

Fig. 1. Four examples of wave structure in the near infrared $\mathrm{OH}$ nightglow emission imaged by the CCD camera during the ALOHA-90 campaign. Each image has been flat fielded to enhance the visibility of the faint displays. Note the similar morphology of the wave patterns except in picture (d) which shows a small scale ripple event. Each image was obtained using an integration time of $20 \mathrm{~s}$.

figure. A similar enhancement in wave activity during the latter half of the night was noticed on several other occasions.

Sometimes much smaller scale wave patterns termed "npple events" [Peterson, 1979] were detected. Figure 1d is an example and it can be seen that the morphology of the wave forms is quite different. In particular, ripples are significantly smaller in geographical extent and have shorter lifetimes (typically $<1$ hour) than the displays discussed above. In this example the average separation of

TABLE 1. Measurements of the average horizontal wave parameters for the four wave patterns shown in Figure 1 (assuming an emission altitude of $87 \mathrm{~km}$ ).

\begin{tabular}{ccccc}
\hline Picture & Date & $\lambda_{\mathrm{x}}(\mathrm{km})$ & $\mathrm{v}_{\mathrm{x}}\left(\mathrm{ms}^{-1}\right)$ & $\tau(\mathrm{min})$ \\
\hline (a) & 21 March & 25 & 47 & 9 \\
(b) & 24 March & 21 & 29 & 12 \\
(c) & 30 March & 23 & 30 & 13 \\
(d) & 20 March & 14.5 & 46 & 5.3 \\
\hline
\end{tabular}

the wave crests was $14.5 \mathrm{~km}$ and the wave packet moved with a uniform velocity of $46 \mathrm{~ms}^{-1}$ indicating an apparent period of $5.3 \mathrm{~min}$, close to the local Brunt-Väisälä period. Unlike the larger scale motions, ripples are thought to be caused by localised regions of strong wind shear generating Kelvin-Helmholtz instabilities in the mesosphere.

\section{Discussion}

Wave displays of comparable morphology and dynamics to the examples shown in Figure 1 were detected on many occasions during ALOHA-90, and the subsequent new moon period, indicating a wealth of short period mesospheric wave structure over the Hawaiian islands. In particular the patterns shown in Figure 1a,b,c exhibit good correspondence with the mid-latitude wave patterns termed "stripes" [Taylor and Henriksen, 1989]. The principal features of this type of display are:

Horizontal wavelength: $20-70 \mathrm{~km}$, Horizontal velocity: $10-50 \mathrm{~ms}^{-1}$, Lateral extent $>500 \mathrm{~km}$, Duration: 0 5-2 hours. 
The majority of the reports detailing measurements of mid and high latitude wave structure are of this type. Experimental and theoretical investigations indicate that many of the patterns are induced by the passage of short period (10-20 $\mathrm{min}$ ) gravity waves through the nightglow layers e.g. Taylor et al. [1987]. As similar wave motions were also detected over the Hawaiian islands this suggests that the sources of short period gravity waves are plentiful and can occur at any latitude.

Nearly all of the mid-latitude observations were made either from high altitude mountain sites (to facilitate the seeing conditions) or in the vicinity $(<500 \mathrm{~km})$ of large mountainous regions. Wave activity in the upper troposphere and lower stratosphere is considerably enhanced over mountain regions compared with the oceans. Much of this enhancement has been attributed to the interaction between strong tropospheric winds and the surface topography generating gravity waves (mainly in the lee of the mountains). Schoeberl [1985] has modelled the propagation of mountain waves through the stratosphere and mesosphere up to an altitude of $70 \mathrm{~km}$. He determined that orographically induced gravity waves with horizontal scale sizes greater than $30 \mathrm{~km}$ may penetrate freely into the upper atmosphere.

If mountains are a primary source of the short period wave motions seen in the nightglow emissions then it is reasonable to expect considerably less wave activity over a remote oceanic site such as the Hawaiian islands (which are over $3,000 \mathrm{~km}$ from any sizeable land mass) than over a large mountainous region such as the Rockies. During both observing periods NIR wave structure was imaged on a remarkably high percentage of nights (nearly every night, but not all night). This compares with typically $30-80 \%$ of the clear sky observing time at mid-latitudes, depending on site and season. This suggests that there are similar type sources for the waves observed over the Hawaiian islands and over large mountainous region.

However, as the Hawaiian islands themselves consist of several high volcanic mountains then prevailing winds blowing over local island peaks (such as Haleakala Crater) may be a rich source of gravity waves. Balsley and Carter, [1989] and Hines, [1989] have investigated the properties of mountain waves observed in the upper troposphere and lower stratosphere. Whether these waves propagate significant amounts of energy into the upper mesosphere is not proven. Due to the isolated location of the Hawaiian islands any gravity waves generated by topographic forcing should be distinguishable from waves of meteorological (or other) origin as they should be observed primarily downwind of the source mountain(s) and should feature near zero phase speeds (since mountain waves are stationary), and curved wave crests (as the wave patterns are viewed at a range of only a few hundred $\mathrm{km}$ ). Although curved wave patterns were observed on some occasions (Figure 1a) the majority of the displays were highly linear and often extended over much of the sky including the zenith (Figure 1c). Furthermore, all of the displays examined so far have exhibited substantial horizontal motion (see Table 1) and no preferred direction of propagation indicating other sources for the waves.
Compared with data recently obtained using the same instruments at a mountain site near Nederland, Colorado $\left(40.0^{\circ} \mathrm{N}, 105.6^{\circ} \mathrm{W}\right)$ the wave patterns imaged during ALOHA-90 were of significantly lower contrast $(<10 \%)$ and proved quite difficult to detect. During the subsequent new moon period the contrast of the displays was considerably higher. In the OI $(557.7 \mathrm{~nm})$ emission similar morphology wave patterns were imaged on several occasions during this period, but only once during ALOHA-90. Unfortunately the CCD camera was not available for the second observing interval and a quantitative comparison of the intensity and contrast of the patterns can not be made. However, the marked improvement in contrast manifested itself as an apparent increase in wave activity as detected by the $\mathrm{OH}$ all-sky camera. Figure 2 plots the number of hours wave structure was detected somewhere within the all-sky field ( $500 \mathrm{~km}$ circular) for both new moon periods. Due to the good seeing conditions observations were possible on most nights. Wave structure was detected on nearly every
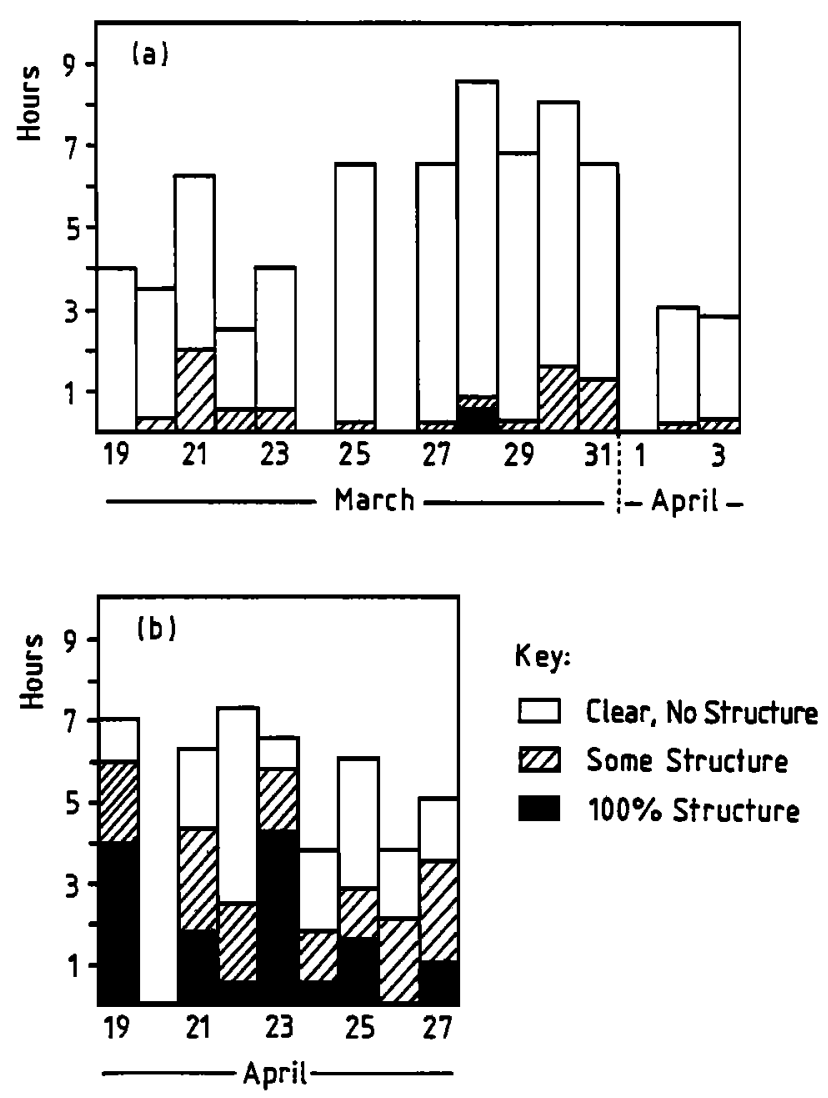

Fig. 2. Histogram plots the number of hours NIR wave structure was detected somewhere within the all-sky field for (a) the ALOHA-90 campaign and (b) the subsequent new moon period. The solid areas indicate when structure was detected over the whole sky while the shaded areas signify the presence of some structure within the camera field but not the amount. (Note CCD data were obtained for longer periods of time than indicated in (a) due to the higher sensitivity of the camera.) 
occasion but many more high contrast displays were observed after the spring equinox.

As well as this temporal increase, the all-sky data indicate wave forms over a larger spatial area. This effect may be directly related to the higher contrast of the structures or it may indicate an increase in the number of potential sources in the vicinity of the Hawaiian islands. For tropospheric wave sources an alternative possibility is that the background winds in the stratosphere and lower mesosphere changed significantly in the interval between the two observing periods. The COSPAR atmospheric model for $20^{\circ} \mathrm{N}$ indicates a mean zonal wind component in March around $40 \mathrm{~ms}^{-1}$ at $\sim 60 \mathrm{~km}$ height. Depending on the direction of propagation, waves with phase speeds lower than this peak value will be strongly attenuated in the lower mesosphere. However, in April this wind drops to less than $20 \mathrm{~ms}^{-1}$ and waves of lower phase speed (similar to those regularly seen in the nightglow emissions) may propagate freely into the upper atmosphere. The fact that wave structure was detected frequently in both the $\mathrm{OH}$ and the $\mathrm{OI}(557.7 \mathrm{~nm})$ emissions during the post equinox period supports the argument for freely propagating wave motions possibly of meteorological origin. However, during ALOHA-90 there is also good evidence for the in situ generation of short period waves [Taylor and Edwards, 1991].

\section{Summary}

Short period ( $<20 \mathrm{~min}$ ) mesospheric wave structure frequently exists at low-latitudes over the Hawaiian islands (at least around the spring equinox). Many of the wave patterns imaged were highly coherent and exhibited similar morphology and dynamics to the nightglow displays seen at mid and high latitudes.

The search for mountain waves induced by the interaction of surface winds with the local island topography is continuing. However, the evidence obtained so far suggests (but is by no means conclusive) that gravity waves generated by this mechanism may not be an important source of the short period wave motions seen in the upper atmosphere. For waves of meteorological origin wind filtering in the intervening atmosphere may play a critical role in governing the visibility of wave patterns of low phase speed.

Acknowledgements. We are most grateful to the director J. Dryden and staff of Holmes and Narver Inc. for arranging the use of the DOE facility on Haleakala Crater for the measurements. In particular we thank K. Hiner and L. Yamaguchi for their logistic support. We acknowledge $\mathrm{V}$. Taylor for assistance during the observations and R. Edwards for help with the data analysis. Funding for this project was provided by University of Cincinnati as part of the U.S. Air Force Office of Scientific Research MAPSTAR programme.

\section{References}

Armstrong, E.B., Irregularities in the $80-100 \mathrm{~km}$ region: A photographic approach, Radio Sci., 21, 313-318, 1986.

Balsley, B.B., and D.A. Carter, Mountain waves in the tropical Pacitic atmosphere: a comparison of vertical wind fluctuations over Pohnpei and Christmas island using VHF wind profilers, J. Atmos. Sci., 46, 2698-2715, 1989.

Clairemidi, J., M. Herse, and G. Moreels, Bi-dimensional observation of waves near the mesopause at auroral latitudes, Planet. Space Sci., 33, 1013-1022, 1985.

Gardner, C.S., Introduction to ALOHA-90: the airborne lidar and observations of the Hawaiian airglow campaign, Geophys. Res. Lett., this issue, 1991.

Hines, C.O., Tropopausal mountain waves over Arecibo: a case study, J. Atmos. Sci., 46, 476-488, 1989.

Moreels, G., and M. Herse, Photographic evidence of waves around the $85 \mathrm{~km}$ level, Planet. Space Sci., 25, 265-273, 1977.

Peterson, A.W., Airglow events visible to the naked eye, Appl. Optics, 22, 3390-3393, 1979.

Peterson, A.W., and L.M. Kieffaber, Infrared photography of $\mathrm{OH}$ airglow structures, Nature, 242, 321-322, 1973.

Schoeberl, M.R., The penetration of mountain waves into the middle atmosphere, J. Atmos. Sci., 42, 2856-2864, 1985.

Taylor, M.J., M.A. Hapgood, and P. Rothwell, Observations of gravity wave propagation in the OI $(557.7 \mathrm{~nm})$, $\mathrm{Na}(589.2 \mathrm{~nm})$ and the near infrared $\mathrm{OH}$ nightglow emission, Planet. Space Sci., 35, 413-427, 1987.

Taylor, M.J. and K. Henriksen, Gravity wave studies at polar latitudes, in Electromagnetic Coupling in the Polar Clefts and Caps, edited P.E. Sandholt and A. Egeland, pp. 421-434, Kluwer Academic Pub., Dordrecht, 1989.

Taylor, M.J. and R. Edwards, Observations of short period mesospheric wave patterns; evidence for in situ wave generation?, Geophys. Res. Lett., this issue, 1991.

Taylor, M.J., D.N. Turnbull, and R.P. Lowe, Coincident imaging and spectrometric observations of zenith $\mathrm{OH}$ nightglow structure, Geophys. Res. Lett., this issue, 1991.

M.J. Taylor and M.J. Hill, Physics Department, The University of Southampton, Southampton, SO9 5NH, U.K.

(Received April 5, 1991; accepted May 7, 1991.) 